\title{
Zwei neue deutsche Tomicus-Arten
}

\author{
beschrieben von
}

Oberförster Eichhoff in Hoeven.

Tomicus amitinus: Elongatus, nitidus, thorace ovato lateribus versus apicem leniter convergentibus rotundatisque, postice pro. fundius punctato, linea basali media levi; elytris fortiter lineatopunctatis, interstitiis planis, rugulosis punctorumque serie ornatis; declivitate postica oblique excavata, fundo nitido, profunde punctalo, margine apicali prolongato, laterali utrinque 4-dentato, dente tertio majore, primo interstitium primum determinante. - Long. 4,3 millim.

Diese dem $\boldsymbol{T}$. typographus und cembrae ähnliche Art fand sich unter Borkenkäfern, die ich vor Jahren in der Umgegend von Schleusingen im Thüringer Wald sammelte. Von den verwandten Arten unterscheidet sich die vorliegende durch die von hinten nach vorn gleichmäfsig gerundeien, merklich convergirenden Seilen des Brustschildes; die Näthe auf der Innenfläche des eiförmigen Fühlerknopfes sind wenig nach vorn gekrümmt, fast gerade, die Intervalle der Punktstreifen auf den Flïgeldecken haben eine Reihe deutlicher Punkte, der Absturz ist glänzend, ziemlich tief punktirt mit stark verlängertem Spitzenrand; auf der Stirn befindet sich ein wenig in die Augen fallendes glattes, kahles Fleckchen.

Tomicus omissus: Cylindricus, thorace postice profundius punctato disco utrinque leniter oblique impresso; elytris fortiler punctalo-slriatis, interstitiis punctorum serie ornatis, postice abrupte truncato retusis, relusionis spatio circulari, margine crenulato dentibusque utrinque quaternis limitato; antennarum capitulum an. nulis primo et secundo longitudine aequalibus, tertio minuto. Long. 3,5 millim.

Auch diese dem $\boldsymbol{T}$. laricis äufserst nahe stehende Art gehört unserer deutschen Fauna an, und fand sich unter zahlreichen, bei 
Neustadt-Eberswalde gesammelten Individuen des $\boldsymbol{T}$. laricis, von dem sie sich durch etwas gedrungenere Form, durch die beiden allerdings schwachen Quereindrücke des Brustschildes. andere Gröfsenverhälınisse an den Ringeln der Fühlerkeule und besonders durch die Bezahnung des Flügelabsturzes unterscheidet. Während nämlich bei laricis anfser dem obersten kleinen Zähnchen der ersten Intervalle, beiderseits am Seitenrand constant, nur zwei grös. sere, etwas von dem gekerbten Seitenrand abgerückte Zähnchen sich befinden, stehen hier in dem gekerbten Seilenrand (also nicht davon abgerückt) beiderseits drei deutliche $Z$ ähnchen, indem der bei $\boldsymbol{T}$. laricis leere Raum zwischen den beiden unteren Zähnen noch ein drittes Zähnchen Irägt. Die Art sieht dadurch dem 'T. proximus $\boldsymbol{m}$. und $\operatorname{dem} \boldsymbol{T}$. rectangulus $\boldsymbol{m}$. sehr ähnlich. von denen sie jedoch in den Näthen der Fühlerkeule abweichı.

A $n$ h a $n g$.

Bei dieser Gelegenheit will ich auf zwei neue europäische Crypturgus-Arten aufmerksam machen.

Crypturgus mediterraneus: Elongatus, cylindricus, subnitidus, niger, antennis et larsis ferrugineis, thorace subelongato, basi truncato, lateribus rectis parallelis, dorso minus conferlim sublilissime punclato, linea media levi; elytris fortiter punctato - striatis, punctis valde dilatatis, interstitiis angustis (subcarinato) elevatis punctorum serie vix conspicua ornatis. - Long. 1,4 millim.

Die Art ist in Mehrzahl bei St. Tropez, Hyères auf Pinus halepensis von Mr. Puton erbeutet, welcher auch bereits die vorstehende, von mir entworfene Diagnose in den Petites Nouv. Entom. No. 11. 1869 der Oeffentlichkeit übergeben hat.

Crypturgus dubius: Subelongatus, cylindricus. subnitidus, niger antennis pedibusque ferrugineis, thorace latiludine longiore, basi truncato, lateribus ultra medium rectis, dein rolundato angustatis, dorso minus confertim subtiliter punctato; elytris minus profunde sed late punctato-strialis, interstitiis planiusculis. - Long. 1,5 millim.

Patria: Pyrenaei. 


\section{$2 \mathrm{BHL}$ Biodiversity Heritage Library}

Eichhoff, Oberförster. 1871. "Zwei neue deutsche Tomicus $\square$ Arten.'Berliner entomologische Zeitschrift / herausgegeben von dem Entomologischen Vereine in Berlin 15(2ロ3),138-139. https://doi.org/10.1002/mmnd.18710150206.

View This Item Online: https://www.biodiversitylibrary.org/item/36395

DOI: https://doi.org/10.1002/mmnd.18710150206

Permalink: https://www.biodiversitylibrary.org/partpdf/210087

\section{Holding Institution}

Smithsonian Libraries

\section{Sponsored by}

Smithsonian

\section{Copyright \& Reuse}

Copyright Status: Public domain. The BHL considers that this work is no longer under copyright protection.

This document was created from content at the Biodiversity Heritage Library, the world's largest open access digital library for biodiversity literature and archives. Visit BHL at https://www.biodiversitylibrary.org. 